\title{
Comparative outcome analysis of trauma and non-trauma emergency laparotomy using a modified NELA tool format
}

\author{
R Naidoo, ${ }^{1,2}$ iD MP Faurie, ${ }^{1,3}$ iD GV Oosthuizen, ${ }^{1,2}$ iD TC Hardcastle ${ }^{1,4}$ iD \\ ${ }^{1}$ Department of Surgery, Nelson R Mandela School of Medicine, University of KwaZulu-Natal, South Africa \\ ${ }^{2}$ Department of General Surgery, Ngwelezana Hospital, South Africa \\ ${ }^{3}$ Faurie, Skinner and Partners Inc., Busamed Hillcrest Private Hospital, South Africa \\ ${ }^{4}$ Trauma Service, Inkosi Albert Luthuli Central Hospital, South Africa
}

Corresponding author, email: ravi@drnaidoo.co.za

Background: Emergency laparotomy (EL) encompasses a diverse range of procedures that general surgeons commonly perform for both trauma and non-trauma related conditions in South Africa (SA). Despite differences in the underlying pathology and influence of the surgical procedure, these patients share one care pathway for preoperative, operative and postoperative care. This study reviewed patients undergoing trauma EL and non-trauma EL in a general surgery setting at a rural KwaZulu-Natal tertiary hospital to compare results between the groups using a modified National Emergency Laparotomy Audit (NELA) tool format.

Methods: Consecutive adult patients undergoing midline EL at Ngwelezana Hospital between 1 March and 31 May 2018 were included. Patient factors analysed were demographic data (age, gender) and risk factors: National Confidential Enquiry into Perioperative Deaths (NCEPOD) grade, American Society of Anesthesiologists (ASA) grade, and comorbidity. Process of care factors included grade of the physician, time to surgery, time of surgery and duration of surgery. The primary outcome measure was mortality. Secondary outcome measures were intensive care unit (ICU) admissions, complications, and length of stay (LOS) $>14$ days.

Results: The study included 110 participants who met the inclusion criteria representing a total of 174 laparotomies. The trauma EL group had lower ASA grades $(p=0.003)$, less comorbidities $(p=0.002)$, more often went to theatre within six hours $(42 / 56 ; 75.0 \%)(p<0.001)$, more admissions to ICU $(23 / 56 ; 41.1 \%)(p<0.001)$, more complications $(29 / 56$; $51.8 \%)(p=0.039)$, and higher length of stay $>14$ days $(16 / 56 ; 28.6 \%)(p=0.037)$.

Conclusion: The trauma EL group represents a high-risk group for morbidity and mortality at Ngwelezana Hospital.

Keywords: emergency laparotomy, NELA, audit

\section{Introduction}

Patients undergoing emergency laparotomy (EL) represent a high-risk group with increased morbidity and mortality compared to elective surgery patients. ${ }^{1}$ EL encompasses a diverse range of procedures that general surgeons commonly perform for both trauma and non-trauma related conditions in South Africa (SA). Surgeons experience a high-volume presentation of trauma patients with penetrating abdominal injuries that adds to the perioperative risk due to the severity of the injury and is strongly associated with death and unplanned critical care admissions. ${ }^{2}$

Despite differences in the underlying pathology and influence of the surgical procedure, trauma EL patients and non-trauma EL patients share one care pathway. They use the same facilities for preoperative assessment, anaesthesia, operating rooms, post-anaesthetic recovery, and hospital wards. $^{3}$ This approach is adequate for most patients but might not meet the needs of trauma patients at high risk of complications and death. A recent national study, however, suggests that non-communicable diseases (NCD) have a larger proportional contribution to surgical mortality in SA than infectious diseases and injuries. ${ }^{2}$

In the United Kingdom (UK), the National Emergency Laparotomy Audit (NELA) which is an ongoing clinical audit, collects data from participating hospitals. The initial paper-based NELA tool has evolved into a web-tool for direct capture of data. The aim is to enable the improvement of the quality of care for patients undergoing EL through the provision of high-quality comparative data from all providers of EL. However, NELA excludes trauma EL patients from the audit. Instead, the Trauma Emergency Laparotomy Audit (TELA) addresses this gap in data collection in the UK. With no national database on non-cardiac surgical outcomes in the public or private sector in SA, the degree to which this variation exists here is not currently known. ${ }^{4}$ This study aims to compare outcomes between trauma EL and non-trauma EL participants in a general surgery setting at a rural KwaZulu-Natal tertiary hospital using a modified NELA tool format. 


\section{Methods}

\section{Study design and setting}

Data was collated retrospectively on surgical patients undergoing midline EL from 1 March 2018 to 31 May 2018 from a prospectively maintained database using a modified NELA tool. The paper-based version (updated 06 October 2010) of the NELA tool was modified in line with local terminology and practices as indicated in Table I. This study was conducted at Ngwelezana Hospital, a 554 bedded hospital, designated as a Tertiary Hospital. The hospital receives referrals from 19 hospitals in the region.

\section{Study sample}

The study comprised all adult male and female patients undergoing midline EL during the study period and included follow-up for 30 days in-hospital from index EL.

\section{Data source and data description}

All data obtained are from existing hospital records including the theatre register, the patient notes, and operative notes. The research assistant extracted the relevant information and recorded it on a separate modified NELA data collection sheet for each patient. The data was transcribed to a Microsoft Access database (Microsoft Corp, Redmund WA). Non-anonymous data remained secure and only accessible to the investigator and assistant.

\section{Data analysis}

All analyses were performed using SPSS software version 24.0 (IBM, Chicago Il.) and report the prevalence and 95\% confidence intervals for outcomes of interest. Crosstabulations and Pearson's chi-square tests were performed to assess associations between categorical variables.
Independent sample t-tests were performed to compare continuous normal variables between two groups and analysis of variance (ANOVA) tests for more than twogroup comparisons. Non-parametric equivalent tests were used where data did not meet assumptions. Proportions were compared between trauma EL and non-trauma EL using Pearson's chi-square tests. Student's t-tests were used for continuous data or means where normally distributed. A $p$-value of $<0.05$ indicated statistical significance.

\section{Results}

\section{Population}

One hundred and twenty (120) consecutive adult participants were identified, of which 110 were included in the sample, i.e., ten participants were excluded due to index EL performed before the study period or missing records.

\section{Participant factors}

Baseline characteristics and 30-day in hospital mortality were compared between the trauma EL and non-trauma EL groups and recorded variables analysed for differences between the groups in Table II. The mean age of the trauma EL group was 33.4 years (SD 11.8) and the non-trauma EL group was 38.2 years (SD 15.7) and was not statistically significant. Males comprised $79(71.8 \%)$ and females 31 (28.2\%) of the total cohort. Risk factors that were statistically significant between the groups were ASA grade $(p=0.003$, Fischer's exact test) and the presence of comorbidity $(p=0.002$, Pearson's chi-square).

\section{Precipitating factors}

Table III outlines the frequency distribution of cases based on mechanism of injury and intraoperative diagnosis between

\begin{tabular}{|c|c|}
\hline NELA tool & Modified NELA tool \\
\hline $\begin{array}{l}\text { Admitting speciality: } \\
\square \text { General surgery } \\
\square \text { Psychiatry } \\
\square \text { Orthopaedics } \\
\square \text { Urology } \\
\square \text { Medicine }\end{array}$ & Omitted \\
\hline None & Comorbid conditions: \\
\hline $\begin{array}{l}\text { Grade of most senior surgeon present in theatre whether } \\
\text { operating or supervising: } \\
\square \text { Consultant } \\
\square \text { Post-CCT Fellow } \\
\square \text { SAS Grade Research Fellow } \\
\square \text { Clinical Fellow } \\
\square \text { Speciality trainee/registrar } \\
\square \text { Core trainee/SHO } \\
\square \text { Other...... }\end{array}$ & $\begin{array}{l}\text { Grade of most senior surgeon present in theatre whether } \\
\text { operating or supervising: } \\
\square \text { Senior consultant } \\
\square \text { Junior consultant } \\
\square \text { Registrar } \\
\square \text { Medical officer grade } \\
\square \text { Community service doctor } \\
\square \text { Other (specify): }\end{array}$ \\
\hline $\begin{array}{l}\text { Goal directed fluid therapy: (e.g. Doppler, Lidco, etc.) } \\
\text { Y } \quad \mathrm{N}\end{array}$ & Omitted \\
\hline $\begin{array}{l}\text { Required level of postop care following surgery: } \\
\square \text { Level } 3 \text { (ICU) } \\
\square \text { Level } 2 \text { (HDU) } \\
\square \text { Level } 1 \text { (Ward) } \\
\square \text { PACU }\end{array}$ & $\begin{array}{l}\text { Required level of postop care following surgery: } \\
\square \text { Level } 3 \text { (ICU) } \\
\square \text { Level } 2 \text { (HCU) } \\
\square \text { Level } 1 \text { (Ward) }\end{array}$ \\
\hline
\end{tabular}

Paper-based version: NELA tool updated 06 October 2010 


\begin{tabular}{|c|c|c|c|c|c|c|c|}
\hline & \multicolumn{2}{|c|}{ All patients } & \multicolumn{2}{|c|}{ Trauma EL } & \multicolumn{2}{|c|}{ Non-trauma EL } & \multirow{2}{*}{$\begin{array}{c}\begin{array}{c}\text { Trauma vs } \\
\text { non-trauma }\end{array} \\
p \text {-value }\end{array}$} \\
\hline & $n(\%)$ & Mortality (\%) & $n(\%)$ & Mortality (\%) & $n(\%)$ & Mortality (\%) & \\
\hline All patients & $110(100)$ & $18(16.3)$ & $56(100.0)$ & $12(21.4)$ & $54(100.0)$ & $6(11.1)$ & \\
\hline $\begin{array}{l}\text { Age in years (mean, } \\
\text { SD) }\end{array}$ & $35.8(14.0)$ & $43.9(12.3)$ & $33.4(11.8)$ & $42.5(11.1)$ & $38.2(15.7)$ & $46.7(15.2)$ & $0.073 *$ \\
\hline Gender & & & & & & & $0.450 \dagger$ \\
\hline Male & $79(71.8)$ & $13(11.8)$ & $42(75.0)$ & $9(16.1)$ & $37(68.5)$ & $4(7.4)$ & \\
\hline Female & $31(28.2)$ & $5(4.5)$ & $14(25.0)$ & $3(5.3)$ & $17(31.5)$ & $2(3.7)$ & \\
\hline NCEPOD grade & & & & & & & $0.239 \ddagger$ \\
\hline Immediate (minutes) & $10(9.1)$ & $3(2.7)$ & $7(12.5)$ & $3(5.3)$ & $3(5.6)$ & $0(0.0)$ & \\
\hline Urgent (hours) & $93(84.5)$ & $13(11.8)$ & $47(83.9)$ & $8(14.3)$ & $46(85.2)$ & $5(9.3)$ & \\
\hline Expedited (days) & $7(6.4)$ & $2(1.8)$ & $2(3.6)$ & $1(1.8)$ & $5(9.2)$ & $1(1.8)$ & \\
\hline ASA grade & & & & & & & $0.003 \ddagger$ \\
\hline I & $65(59.1)$ & $8(7.3)$ & $37(66.0)$ & $7(12.5)$ & $28(51.8)$ & $1(1.8)$ & \\
\hline II & 15 (13.6) & $2(1.8)$ & $2(3.6)$ & $1(1.8)$ & $13(24.1)$ & $1(1.8)$ & \\
\hline III & $19(17.3)$ & $5(4.5)$ & $8(14.3)$ & $2(3.6)$ & $11(20.4)$ & $3(5.6)$ & \\
\hline IV & $10(9.1)$ & $3(2.7)$ & $8(14.3)$ & $2(3.6)$ & $2(3.7)$ & $1(1.8)$ & \\
\hline $\mathrm{V}$ & $1(0.9)$ & $0(0.0)$ & $1(1.8)$ & $0(0.0)$ & $0(0.0)$ & $0(0.0)$ & \\
\hline Comorbidity present & & & & & & & $0.002 \dagger$ \\
\hline Yes & $43(39.1)$ & $10(9.1)$ & $14(25.0)$ & $6(10.7)$ & $29(53.7)$ & $4(7.4)$ & \\
\hline No & $67(60.9)$ & $8(7.2)$ & $42(75.0)$ & $6(10.7)$ & $25(46.3)$ & $2(3.7)$ & \\
\hline
\end{tabular}

* Student's t-test, $\uparrow$ Pearson's chi-square, $\$$ Fisher's exact test

Table III: Frequency distribution of presenting problem based on mechanism of injury and post-operative diagnosis, and 30-day in-hospital mortality related to trauma EL and non-trauma EL groups

\begin{tabular}{|c|c|c|c|c|c|}
\hline \multicolumn{3}{|c|}{ Trauma EL } & \multicolumn{3}{|c|}{ Non-trauma EL } \\
\hline & $n(\%)$ & Mortality (\%) & & $n(\%)$ & Mortality (\%) \\
\hline All patients & $56(100.0)$ & $12(21.1)$ & All patients & $54(100.0)$ & $6(11.1)$ \\
\hline Blunt & $10(17.9)$ & $4(7.1)$ & Bowel ischaemia & $2(3.7)$ & $2(3.7)$ \\
\hline MVC & $7(12.5)$ & $3(5.3)$ & Complicated appendicitis & $7(13.0)$ & $1(1.85)$ \\
\hline Assault & $3(5.4)$ & $1(1.8)$ & Sigmoid volvulus & $4(7.4)$ & $1(1.85)$ \\
\hline Penetrating & $46(82.1)$ & $8(14.3)$ & Cholecystitis & $2(3.7)$ & $1(1.85)$ \\
\hline Gunshot & $20(35.7)$ & $6(10.7)$ & Bowel perforation & $1(1.85)$ & $1(1.85)$ \\
\hline Stab & $22(39.3)$ & $1(1.8)$ & Uncomplicated appendicitis & $22(40.7)$ & $0(0.0)$ \\
\hline Impaled & $3(5.3)$ & $1(1.8)$ & Perforated peptic ulcer & $4(7.4)$ & $0(0.0)$ \\
\hline \multirow[t]{6}{*}{ Sexual assault } & $1(1.8)$ & $0(0.0)$ & Complicated hernia & $4(7.4)$ & $0(0.0)$ \\
\hline & & & Colon malignancy & $3(5.6)$ & $0(0.0)$ \\
\hline & & & Adhesive bowel obstruction & $2(3.7)$ & $0(0.0)$ \\
\hline & & & Intra-abdominal abscess & $1(1.85)$ & $0(0.0)$ \\
\hline & & & Open drainage of biloma & $1(1.85)$ & $0(0.0)$ \\
\hline & & & Removal of gossypiboma & $1(1.85)$ & $0(0.0)$ \\
\hline
\end{tabular}

trauma EL and non-trauma EL groups, and 30-day mortality. Among the trauma EL participants, penetrating trauma, $46(82.1 \%)$, was the leading mechanism of injury with $20(35.7 \%)$ gunshot injuries and $22(39.3 \%)$ stab injuries. The principal diagnosis in the non-trauma EL group was uncomplicated appendicitis with $22(40.7 \%)$ participants.

\section{Process of care factors}

A total of $64 / 110(58.2 \%)$ participants went to theatre within six hours of admission to the surgical department. Of these,
$42(38.2 \%)$ were in the trauma EL group compared to 22 $(20.0 \%)$ in the non-trauma EL group. Time to surgery was statistically significant ( $p<0.001$, Pearson's chi-square) between the groups. None of the remaining factors analysed showed statistically significant differences, and these findings are presented in Table IV.

\section{Primary outcomes}

The surgical department performed surgery on 56 (50.9\%) trauma and $54(49.1 \%)$ non-trauma participants (Table IV) 
Table IV: Seniority of medical staff, time to surgery, time of day, duration of surgery, and 30-day in-hospital mortality related to trauma EL and non-trauma EL groups

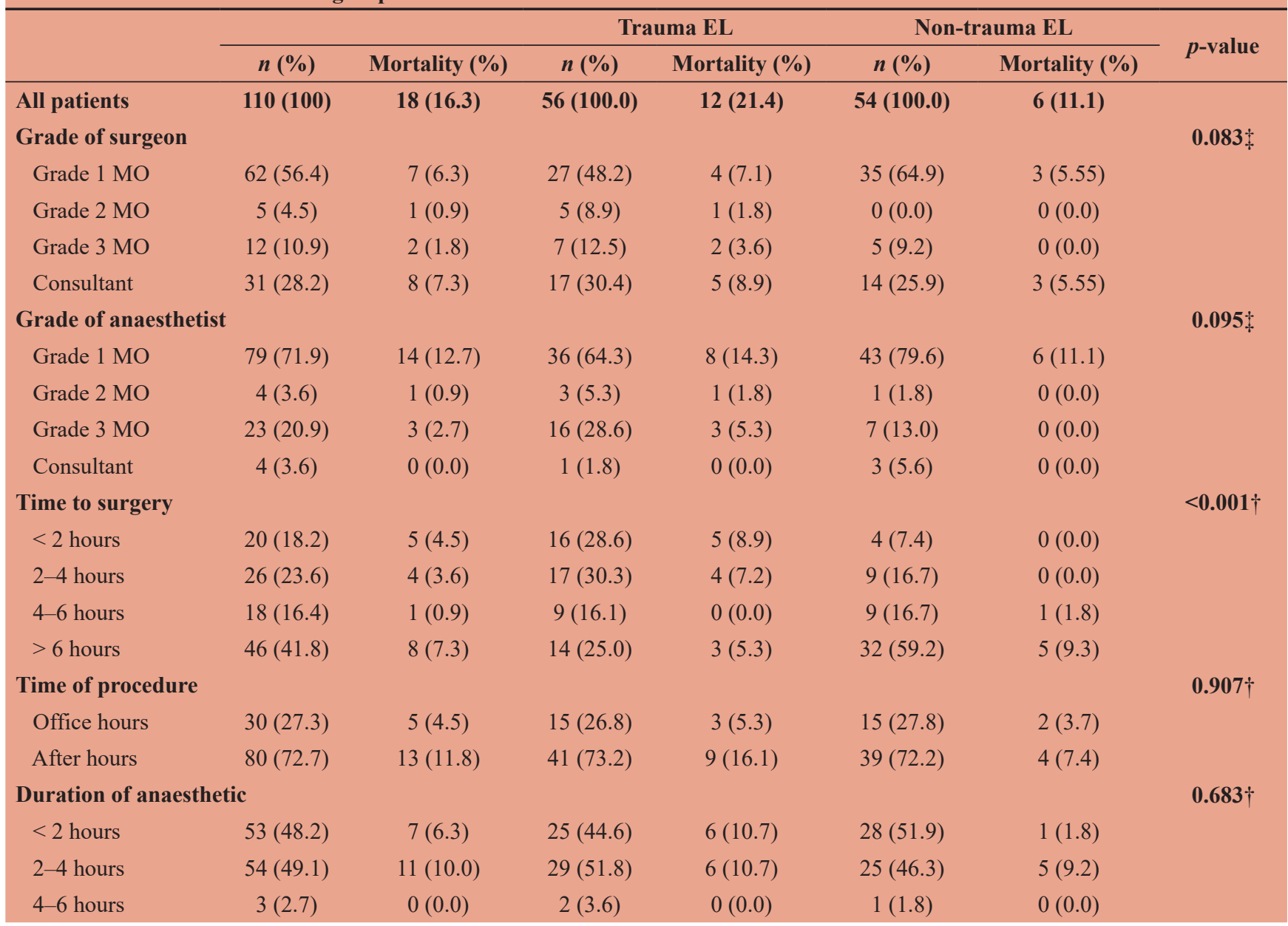

$\dagger$ Pearson's chi-square, $†$ Fisher's exact test

Table V: All laparotomies, postoperative admission to ICU, postoperative complications, length of stay, and 30-day in-hospital mortality related to trauma EL and non-trauma EL groups

\begin{tabular}{|c|c|c|c|c|c|c|c|}
\hline & \multicolumn{4}{|c|}{ Trauma EL } & \multicolumn{2}{|c|}{ Non-trauma EL } & \multirow[b]{2}{*}{$p$-value } \\
\hline & $n(\%)$ & Mortality (\%) & $n(\%)$ & Mortality (\%) & $n(\%)$ & Mortality (\%) & \\
\hline All patients & $110(100)$ & $18(16.3)$ & $56(100)$ & $12(21.4)$ & $54(100)$ & $6(11.1)$ & \\
\hline Single laparotomy & $65(59.1)$ & $4(3.6)$ & $29(51.8)$ & $2(3.6)$ & $36(66.7)$ & $2(3.7)$ & 0.168 \\
\hline One relaparotomy & $34(30.9)$ & $10(9.1)$ & $19(33.9)$ & $7(12.5)$ & $15(27.8)$ & $3(5.6)$ & \\
\hline Two relaparotomies & $6(5.5)$ & $3(2.7)$ & $5(8.9)$ & $3(5.3)$ & $1(1.8)$ & $0(0.0)$ & \\
\hline Three relaparotomies & $2(1.8)$ & $0(0.0)$ & $2(3.6)$ & $0(0.0)$ & $0(0.0)$ & $0(0.0)$ & \\
\hline Four relaparotomies & $3(2.7)$ & $1(0.9)$ & $1(1.8)$ & $0(0.0)$ & $2(3.7)$ & $1(1.8)$ & \\
\hline Highest postop care & & & & & & & $<0.001$ \\
\hline Level 3 (ICU) & $28(25.5)$ & $12(10.9)$ & $23(41.1)$ & $10(17.8)$ & $5(9.2)$ & $2(3.7)$ & \\
\hline Level 2 (high care) & $4(3.6)$ & $2(1.8)$ & $1(1.8)$ & $0(0.0)$ & $3(5.6)$ & $2(3.7)$ & \\
\hline Level 1 (ward) & $78(70.9)$ & $4(3.6)$ & $32(57.1)$ & $2(3.6)$ & $46(85.2)$ & $2(3.7)$ & \\
\hline Postop complication & & & & & & & $0.039 \dagger$ \\
\hline Complication & $47(42.7)$ & $18(16.3)$ & $29(51.8)$ & $12(21.4)$ & $18(33.3)$ & $6(11.1)$ & \\
\hline No complication & $63(57.3)$ & $0(0.0)$ & $27(48.2)$ & $0(0.0)$ & $36(66.7)$ & $0(0.0)$ & \\
\hline LOS & & & & & & & $0.037 \dagger$ \\
\hline LOS $>14$ days & $23(20.9)$ & $10(9.1)$ & $16(28.6)$ & $8(14.3)$ & $7(13.0)$ & $2(3.7)$ & \\
\hline LOS $\leq 14$ days & $87(79.1)$ & $8(7.3)$ & $40(71.4)$ & $4(7.1)$ & $47(87.0)$ & $4(7.4)$ & \\
\hline
\end{tabular}

$\dagger$ Pearson’s chi-square, $₫$ Fisher’s exact test 


\begin{tabular}{|c|c|c|c|c|c|c|}
\hline & \multicolumn{2}{|c|}{ All patients $=110$} & \multicolumn{2}{|c|}{ Trauma $\mathrm{EL}=56$} & \multicolumn{2}{|c|}{ Non-trauma EL = 54} \\
\hline & $n(\%)$ & Mortality (\%) & $n(\%)$ & Mortality (\%) & $n(\%)$ & Mortality (\%) \\
\hline Patients with a complication & $47(42.7)$ & $18(16.3)$ & $29(51.8)$ & $12(21.4)$ & $18(33.3)$ & $6(11.1)$ \\
\hline Systemic sepsis & $18(16.4)$ & $8(7.3)$ & $10(17.9)$ & $4(7.1)$ & $8(14.8)$ & $4(7.4)$ \\
\hline Haemorrhagic shock & $6(5.5)$ & $3(2.7)$ & $6(10.7)$ & $3(5.4)$ & $0(0.0)$ & $0(0.0)$ \\
\hline ARDS & $2(1.8)$ & $2(1.8)$ & $2(3.6)$ & $2(3.6)$ & $0(0.0)$ & $0(0.0)$ \\
\hline Cardiac & $2(1.8)$ & $2(1.8)$ & $1(1.8)$ & $1(1.8)$ & $1(1.9)$ & $1(1.9)$ \\
\hline Aspiration under anaesthesia & $2(1.8)$ & $2(1.8)$ & $1(1.8)$ & $1(1.8)$ & $1(1.9)$ & $1(1.9)$ \\
\hline Renal failure & $1(0.9)$ & $1(0.9)$ & $1(1.8)$ & $1(1.8)$ & $0(0.0)$ & $0(0.0)$ \\
\hline Wound infection & $8(7.3)$ & $0(0.0)$ & $4(7.1)$ & $0(0.0)$ & $4(7.4)$ & $0(0.0)$ \\
\hline Anastomotic leakage & $4(3.6)$ & $0(0.0)$ & $2(3.6)$ & $0(0.0)$ & $2(3.7)$ & $0(0.0)$ \\
\hline Pneumonia & $1(0.9)$ & $0(0.0)$ & $0(0.0)$ & $0(0.0)$ & $1(1.9)$ & $0(0.0)$ \\
\hline Faecal peritonitis & $1(0.9)$ & $0(0.0)$ & $1(1.8)$ & $0(0.0)$ & $0(0.0)$ & $0(0.0)$ \\
\hline Wound dehiscence & $1(0.9)$ & $0(0.0)$ & $1(1.8)$ & $0(0.0)$ & $0(0.0)$ & $0(0.0)$ \\
\hline Fistula & $1(0.9)$ & $0(0.0)$ & $0(0.0)$ & $0(0.0)$ & $1(1.9)$ & $0(0.0)$ \\
\hline
\end{tabular}

with a mean of 1.5 laparotomies per patient, and a range from 1-5 (Table V). Thirty-day in-hospital mortality rate was $18 / 110$ (16.4\%; 95\% CI 10.24-24.90\%). Of these, $12 / 110$ $(10.9 \%)$ were in the trauma EL group, and 6/110 (5.5\%) were in the non-trauma EL group. Trauma participants were more likely to die but this was not statistically significant ( $p=0.144$, Pearson's chi-square).

\section{Secondary outcomes}

Postoperative admission to ICU was 28/110 (25.5\%; 95\% CI 17.85-34.81\%). Postoperative admission to ICU (Table V) was more common in the trauma EL group than in the non-trauma EL group, and this was statistically significant ( $p<0.001$, Fischer's exact test). The ICU median duration of stay was six days (IQR 3-11 days) in the trauma EL group and six days (IQR 4-10 days) in the non-trauma EL group. ICU associated mortality was $12 / 18(66.7 \%$; $95 \%$ CI $41.15-$ $85.64 \%)$. Six out of 18 deaths occurred outside of ICU (33.3\%; 95\% CI 14.36-58.85\%). The overall complication rate was $47 / 110(42.7 \%$; 95\% CI 33.46-52.51\%). Of those in the trauma EL group 29/56 (51.8\%) developed a complication compared to $18 / 54(33.3 \%)$ in the non-trauma EL group, and the difference was statistically significant ( $p=0.039$, Pearson's chi-square). We expound in Table VI postoperative complications showing the frequency distribution and 30-day in-hospital mortality. The median length of hospital stay was six days (IQR 4-17) in the trauma EL group and five days (IQR 3-8) in the non-trauma EL group, and the difference was not statistically significant $(p=0.121)$. However, when the proportion of patients who stayed $>14$ days was compared, the trauma EL group was more likely to stay $>14$ days $(p=0.037$, Pearson's chisquare), which was statistically significant.

\section{Discussion}

The present study shows there are statistically significant differences between the trauma EL and non-trauma EL groups in terms of patient factors, the process of care and postoperative outcomes using a modified NELA tool. The differences in patient ASA grade, presence of comorbidity, time to surgery, morbidity and mortality were statistically significant between the groups. The trauma EL group had lower ASA grades and less comorbidities, went to theatre sooner, yet suffered higher morbidity and mortality. The trauma EL group was more frequently admitted to ICU, experienced more postoperative complications, and was more likely to stay in hospital $>14$ days. These findings suggest that patient-related and system-related factors interact to increase morbidity and mortality risk in the trauma EL group.

The American Society of Anesthesiologists Physical Status (ASAPS) grading system is widely used for classifying surgical patients preoperatively based on their comorbid background. ${ }^{5}$ It is 'user friendly' and does not rely on complicated variables, making it a valuable tool in an acute setting. ${ }^{5}$ In the current study, the non-trauma EL group was older than the trauma EL group by a difference in mean age of 4.8 years, although this difference was not statistically significant. As patients get older coincident diseases are more common resulting in higher ASA grades with age as the current study also shows. In the trauma EL group, twothirds of the participants who died $(66.7 \%)$ were in ASA I and ASA II grades (previously healthy patient/mild systemic disease), in comparison to the non-trauma EL group where two-thirds of the participants who died (66.7\%) were in ASA III grade (patient with severe systemic disease) and above. We found higher mortality in the trauma EL group despite statistically significant lower ASA grades and comorbidity. A recent study also looking at the relationship between the ASA score and postoperative mortality has concluded that it has poor discriminatory power and 'is less than acceptable' 6 for widespread use.

The urgency of surgery has a far larger proportional contribution to perioperative mortality compared to other surgical risk factors. ${ }^{2}$ The urgent response of an emergency medical service (EMS) is essential for the initiation of resuscitation, rapid transfer of the patient to definitive care facilities and prevention of further physiological deterioration. ${ }^{7}$ The time required to optimise a patient must be balanced against the risk of delays for time-sensitive pathologies. ${ }^{8}$ Data from NELA shows that around $50 \%$ of patients have a surgical urgency $<6$ hours, 33\% 6-18 hours and $17 \%>18$ hours. ${ }^{9}$ In the current study, $42 / 56$ (75\%) of 
participants in the trauma EL group went to theatre $<6$ hours from admission, and the overall mortality in this group was $9 / 12(75 \%)$. Well documented factors that may contribute to this finding are high injury severity score, inadequate resuscitation before the operation and delayed presentation to a definitive care facility.

The ability of a hospital to recognise and 'rescue' surgical patients influences surgical mortality and the development of complications. ${ }^{10}$ The trauma EL group accounted for 12/18 $(66.7 \%)$ of the overall mortality in this study. In the trauma EL group, $2 / 12$ (16.7\%) died after a single laparotomy, and this may be indicative of the severity of the injury. As they were admitted directly to ICU postoperatively, one could conclude that some deaths are inevitable despite the best possible treatment. ${ }^{11}$ Mortality in the trauma EL group operated on by consultants and grade 1 medical officers were 5/12 (41.7\%) and 4/12 (33.3\%) respectively. More severe cases may require consultant input. This applies not only to the technical aspects associated with performing or overseeing the operation but also the decision to operate, or indeed not to proceed. ${ }^{8}$ One study recorded the inadequacies of junior doctors providing trauma care. It showed that they failed to assess the multiply-injured patient correctly in terms of priorities of trauma care. ${ }^{12}$ These findings may suggest that patient condition, on the one hand, and inexperience of junior doctors, on the other hand, may perhaps be contributing factors to mortality in trauma patients in this setting. Another viewpoint might be that delays before transfer to hospital from the scene or via referral hospitals may already have compromised the patient; ${ }^{7}$ therefore, similar outcomes in either hand.

Higher mortalities are also evident in subgroups, including males, those with penetrating trauma and those who have their surgery at night. Male participants accounted for $9 / 12(75 \%)$ of trauma participants who died. Nigerian and Kenyan studies reported that stab, gunshot and motor vehicle collision (MVC) were the three leading causes of abdominal injury affecting predominantly males, which holds correct for the current study. ${ }^{13,14}$ Evidence of peritoneal soiling indicates severe damage and in keeping with the mechanism of penetrating trauma requiring emergency laparotomy in $46 / 56(82 \%)$ in the trauma EL group. The predominance of penetrating injuries differs from international studies, where they see more blunt injuries, ${ }^{15}$ yet is characteristic of the SA trauma burden. Amongst trauma participants who died, 9/12 $(75 \%)$ had their surgery after-hours. A specialist was more likely to be present at operations performed during the day $(51 \%)$ than those at night $(23 \%) .{ }^{16}$ This finding is in keeping with data from the UK and Australia, which suggest that after-hours surgery is associated with worse outcomes than surgery performed during the day. ${ }^{17-21}$

Careful selection and postoperative ICU support can achieve very low mortality in 'high-risk' patients. ${ }^{11}$ A study has recommended that we should directly admit to ICU those with a predicted mortality risk exceeding $10 \%$ on NELA risk prediction tool. ${ }^{22}$ Another study has found that those initially admitted to a general ward following surgery and later transferred to ICU suffered the highest mortality rates. ${ }^{17}$ However, there are no universally accepted or adopted criteria for admitting surgical patients to a critical care unit. ${ }^{11}$ The UK defines ICU requirements by the levels of care that a patient may require, similar to SA..$^{23}$ In the current study, $23 / 56(41.1 \%)$ of participants in the trauma EL group stayed in ICU at some point of their hospital admission. Despite high ICU usage by trauma EL participants, the death rate amongst those admitted to ICU at some point of their hospital admission was 10/12 (83.3\%). There are well-recognised factors that may contribute to ICU associated mortality. In essence, these are unplanned admission to ICU, premature discharge from ICU to a general ward, condition of organ dysfunction and nosocomial complications. ${ }^{24}$

A concerning finding in this study is that $6 / 18(33.3 \%)$ of participants died without ICU intervention at any point during their hospital admission. A system for early detection and response when problems occur in the general wards may be useful. ${ }^{25}$ The validated Triage Early Warning Score (TEWS) system as part of the South African Triage Score (SATS) may be helpful in this regard. TEWS is a composite score of the patient's physiology based on the patient's vital signs. The higher the rating, the more the urgency for escalation of care. The quality of nursing care is central to this and may explain previous studies that showed an association between a high nurse-to-bed ratio and low surgical mortality. ${ }^{26-28}$ Strategies for ensuring timely recognition and effective management of complications will be essential in reducing deaths after inpatient surgery. ${ }^{10}$

Mortality alone is not enough as a quality indicator. Nonfatal outcomes also carry high human and financial costs and should not be disregarded. ${ }^{29}$ Salvage of severely injured trauma patients and the ability to keep them alive may increase the complication rates, also leading to prolonged hospitalisation and higher costs. ${ }^{30}$ Significant injuries and slow recovery after surgery may account for trauma EL participants who required a hospital stay $>14$ days. A study by Ghaferi et al. has shown the early detection of complications and swift intervention in a critical care setting to reduce overall hospital stay. ${ }^{10}$ The initial assessment of the critically injured patient must include consultant surgeons, anaesthetists and intensivists. This collaborative effort may identify the most appropriate ward to care for the patient and enable healthcare teams to achieve the best outcomes for patients in an efficient and operationally sustainable manner.

\section{Limitations}

This study has certain limitations. It was performed in a single tertiary level hospital with a particular demographic and resources, including staffing; therefore, it is not an indication of the magnitude of the problem in the country. During the period under review, the consultant cover at Ngwelezane Hospital was far less than at present, and the findings may not be reflective of the current situation at the hospital. The proportion of patients not operated on because of fitness issues or patient choice is unknown. We could only reliably assess the delay from admission to the surgical department to the start of surgery. At the time of the study, the institutional policy was midline laparotomy for peritonitis due to suspected appendicitis, resulting in the high level of midline laparotomies for uncomplicated appendicitis. The standard of care for uncomplicated appendicitis is laparoscopic management or at least a local right-sided transverse incision, the feasibility and affordability of which are well researched in the South African public service. The three months duration of this study may not be long enough to sufficiently represent the full spectrum of pathology requiring emergency laparotomy prevalent in this community. Only 30-day in-hospital mortality and adverse 
events were captured since a 30-day follow-up in our setting was not feasible.

\section{Conclusion and recommendations}

The trauma EL group represents a high-risk group for morbidity and mortality at Ngwelezana Hospital. Risk stratifying this group for early ICU admission may have the impact of reducing mortality and morbidity, in terms of complications and length of stay at this hospital. Ensuring prompt evaluation with early senior staff involvement, adequate resuscitation, and appropriate levels of postoperative care are all potentially modifiable factors in this group.

\section{Conflict of interest}

The authors declare no conflict of interest.

\section{Funding source}

None.

\section{Ethical approval}

We obtained full ethical approval from the Biomedical Research Ethics Committee (BREC) of the University of KwaZulu-Natal (ref no. BE655/17). Permission to conduct this research was granted by KwaZulu-Natal Department of Health (Health Research Committee) and Ngwelezana Hospital Management.

\section{ORCID}

R Naidoo (iD https://orcid.org/0000-0003-4898-7927 MP Faurie iD https://orcid.org/0000-0002-5485-6985 GV Oosthuizen (iD https://orcid.org/0000-0001-6898-2969 TC Hardcastle (iD https://orcid.org/0000-0002-3967-0234

\section{REFERENCES}

1. Vivekanand KH, Mohankumar K, Prakash D, et al. Clinical outcome of emergency laparotomy: our experience at tertiary care centre (a case series). International Journal of Biomedical and Advance Research. 2015;6(10):709-14. https://doi.org/ 10.7439/ijbar.v6i10.2578.

2. Biccard BM, Madiba TE. The South African Surgical Outcomes Study: a 7-day prospective observational cohort study. S Afr Med J. 2015;105(6):465-75. https://doi.org/10.71 96/SAMJ.9435. PMID: 26716164.

3. Pearse RM, Moreno RP, Bauer P, et al. Mortality after surgery in Europe: a 7-day cohort study. Lancet. 2012;380:1059-65. https://doi.org/10.1016/S0140-6736(12)61148-9. PMID: 2299 8715.

4. Spence RT, Panieri E, Rayne SL, GlobalSurg South Africa collaboration. A multicentre evaluation of emergency abdominal surgery in South Africa: results from the GlobalSurg-1 South Africa study. S Afr Med J. 2016;106(2):163-8. https://doi.org/10.7196/SAMJ.2016.v106 i2.10183. PMID: 26821895.

5. Singaram S, Naidu S. Use of the American Society of Anesthesiologists Physical Status Classification in non-trauma surgical versus trauma patients: a survey of inter-observer consistency. Southern African Journal of Anaesthesia and Analgesia. 2018;24:3:81-5. https://doi.org/10.1080/2220118 1.2018.1470833.

6. Moreno RP, Pearse R, Rhodes A. American Society of Anesthesiologists Score: still useful after 60 years? Results of the EuSOS Study. Revista Brasileira de Terapia Intensiva. 2015;27(2):105-12. https://doi.org/10.5935/0103-507X.2015 0020 . PMID: 26340149 . PMCID: PMC4489777.

7. Chowdhury S, Navsaria PH, Edu S, Nicol AJ. The effect of emergency medical services response on outcome of trauma laparotomy at a Level 1 Trauma Centre in South Africa. S Afr J Surg. 2016;54(4):17-21. PMID: 28272851.

8. Poulton T, Murray D. Pre-optimisation of patients undergoing emergencylaparotomy: a review of best practice. Anaesthesia. 2019;74:100-7. https://doi.org/10.1111/anae.14514. PMID: 30 604422 .

9. Fourth NELA Report. 2018.

10. Ghaferi AA, Birkmeyer JD, Dimick JB. Variation in hospital mortality associated with inpatient surgery. N Eng J Med. 2009;361:1368-75. https://doi.org/10.1056/NEJMsa0903048. PMID: 19797283.

11. Goldhill DR, Down JF. Are we operating as well as we can? Critical care to minimise postoperative mortality and morbidity. Anaesthesia. 2008;63:689-94. https://doi.org/10.11 11/j.1365-2044.2008.05611.x. PMID: 18582252.

12. Sayers RD, Bewes PC, Porter KM. Emergency laparotomy for abdominal trauma. Injury. 1992;23:537-41. https://doi.org/ 0020-1383/92/080537-05. PMID: 1286907.

13. Adejumo AA, Thairu Y, Egenti N. Profile of abdominal trauma in federal teaching hospital, Gombe, North-east, Nigeria: A cross sectional study. International Journal of Innovative Medicine and Health Science. 2015;4:41-5.

14. Kirubel A, Mahteme B, Ayelign T, et al. Laparotomy for abdominal injury indication \& outcome of patients at a teaching hospital in Addis Ababa, Ethiopia. Ethiop J Health Sci. 2019;29:503-12. PMID: 31447524. PMCID: PMC6689 702 .

15. Abhilash KPP, Chakraborthy N, Pandian GR, et al. Profile of trauma patients in the emergency department of a tertiary care hospital in South India. J Fam Med Prim Care. 2016;5:55863. https://doi.org/10.4103/2249-4863.197279. PMID: 28217 583. PMCID: PMC5290760.

16. Steenkamp C, Kong VY, Clarke DL, et al. The effect of systematic factors on the outcome of trauma laparotomy at a major trauma centre in South Africa. Ann R Coll Surg Engl. 2017;99:540-4. https://doi.org/10.1308/rcsann.2017.0079. PMID: 28853585. PMCID: PMC 5697034.

17. Pearse RM, Harrison DA, James P, et al. Identification and characterisation of the high-risk surgical population in the United Kingdom. Crit Care. 2006. https://doi.org/10.1186/ cc4928. PMID: 16749940. PMCID: PMC1550954.

18. Semmens JB, Aitken RJ, Sanfilippo FM, et al. The Western Australian Audit of Surgical Mortality: advancing surgical accountability. Med J Aust. 2005;183(10):504-8. PMID: 16296962.

19. Cullinane M, Gray AJG, Hargraves CMK, et al. The 2003 Report of the National Confidential Enquiry into Perioperative Deaths. 2003.

20. Emergency General Surgery: The Future: A Consensus Statement. 2007.

21. Cook TM, Day CJE. Hospital mortality after urgent and emergency laparotomy in patients aged $65 \mathrm{yr}$ and over. Risk and prediction of risk using multiple logistic regression analysis. 1998;80:776-81. Available from: https://academicoupcom/bj a/article-abstract/109/3/368/273770.

22. Fifth NELA Report. 2019.

23. Society TIC. Levels of critical care for adult patients, London. The Intensive Care Society. 2002. 
24. Lin W-T, Chen W-L, Chao C-M, Lai C-C. The outcomes and prognostic factors of the patients with unplanned intensive care unit readmissions. Medicine. 2018;97:26. https://doi. org/10.1097/MD.0000000000011124. PMID: 29952954. PMCID: PMC6039646.

25. Bellomo R, Goldsmith D, Uchino S, et al. Prospective controlled trial of effect of medical emergency team on postoperative morbidity and mortality rates. Crit Care Med. 2004;32(4):916-21. https://doi.org/10.1097/01.CCM.0000119 428. 02968.9E. PMID: 15071378.

26. Aiken LH, Clarke SP, Sloane DM, et al. Hospital nurse staffing and patient mortality, nurse burnout, and job dissatisfaction. JAMA. 2002;288(16):1987-93.https://doi.org/10.1001/jama.2 88.16.1987. PMID: 12387650.

27. Sasichay-Akkadechanunt T, Scalzi CC, Jawad AF. The relationship between nurse staffing and patient outcomes. J Nur
Adm. 2003;33(9):478-85. https://doi.org/10.1097/00005110200309000-00008. PMID: 14501564.

28. Carayon P, Gurses AP. A human factors engineering conceptual framework of nursing workload and patient safety in intensive care units. Intensive Crit Care Nurs. 2005;21(5):284. https:// doi.org/10.1016/j.iccn.2004.12.003. PMID: 16182125 .

29. Anderson JE, Rose J, Noorbakhsh A, et al. An efficient risk adjustment model to predict inpatient adverse events after surgery. World J Surg. 2014;38(8):1954-60. https://doi. org/10.1007/s00268-014-2490-6. PMID: 24615608.

30. Mondello S, Cantrell A, Italiano D, et al. Complications of trauma patients admitted to the ICU in Level I Academic Trauma Centers in the United States. BioMed Res Int 2014;2014.https://doi.org/10.1155/2014/473419.PMID: 2499 5300. PMCID: PMC4065752. 